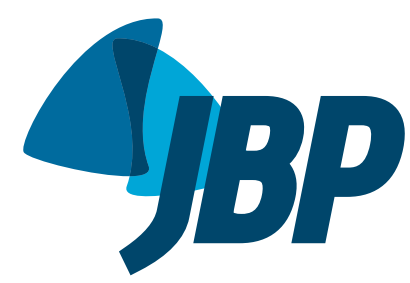

1. Programa de Controle da Asma e Rinite Alérgica da Bahia - ProAR - Salvador (BA) Brasil.

2. Programa de Pós-Graduação em Ciências da Saúde, Universidade Federal da Bahia, Salvador (BA) Brasil.

3. Escola Bahiana de Medicina e Saúde Pública, Salvador (BA) Brasil.

4. Departamento de Pediatria, Faculdade de Medicina, Universidade Federal da Bahia, Salvador (BA) Brasil.

5. Programa de Pós-Graduação em Medicina e Saúde, Universidade Federa da Bahia, Salvador (BA) Brasil.

Submitted: 3 May 2015.

Accepted: 31 May 2016

Study carried out under the auspices of the Programa de Controle da Asma e Rinite Alérgica da Bahia - ProAR Salvador (BA) Brasil.

\section{Association between severe asthma and changes in the stomatognathic system}

\author{
Mayra Carvalho-Oliveira', ${ }^{1,2}$ Cristina Salles ${ }^{3}$, Regina Terse ${ }^{4}$, \\ Argemiro D’Oliveira Júnior ${ }^{2,5}$
}

\section{ABSTRACT}

Objective: To describe orofacial muscle function in patients with severe asthma. Methods: This was a descriptive study comparing patients with severe controlled asthma (SCA) and severe uncontrolled asthma (SUA). We selected 160 patients, who completed a sociodemographic questionnaire and the 6-item Asthma Control Questionnaire (ACQ-6), as well as undergoing evaluation of orofacial muscle function. Results: Of the 160 patients evaluated, 126 (78.8\%) and 34 (21.2\%) presented with SCA and SUA, respectively, as defined by the Global Initiative for Asthma criteria. Regardless of the level of asthma control, the most frequent changes found after evaluation of muscle function were difficulty in chewing, oronasal breathing pattern, below-average or poor dental arch condition, and difficulty in swallowing. When the sample was stratified by $\mathrm{FEV}_{1}$ (\% of predicted), was significantly higher proportions of SUA group patients, compared with SCA group patients, showed habitual open-mouth chewing $(24.8 \%$ vs. $7.7 \% ; p<0.02)$, difficulty in swallowing water $(33.7 \%$ vs. $17.3 \% ; p<0.04)$, and voice problems (81.2\% vs. $51.9 \% ; p<0.01)$. When the sample was stratified by ACQ-6 score, the proportion of patients showing difficulty in swallowing bread was significantly higher in the SUA group than in the SCA group (66.6\% vs. $26.6 \%$; $p<0.01)$. Conclusions: The prevalence of changes in the stomatognathic system appears to be high among adults with severe asthma, regardless of the level of asthma control. We found that some such changes were significantly more common in patients with SUA than in those with SCA.

Keywords: Speech/physiology; Stomatognathic system/physiopathology; Asthma/ complications; Deglutition disorders; Mastication/physiology.
\end{abstract}

\section{INTRODUCTION}

The 2015 update of the Global Initiative for Asthma (GINA) guidelines ${ }^{(1)}$ indicates that, in $10-40 \%$ of patients with (allergic or non-allergic) asthma, the disease may be associated with rhinitis. However, a study conducted at a referral center in the city of Salvador, Brazil, found a 100 percent association between asthma and allergic rhinitis. ${ }^{(2)}$ Allergic rhinitis, in turn, can cause nasal obstruction, with consequent oral breathing at rest, even when individuals with severe asthma are experiencing stable periods. ${ }^{(3)}$ Oral breathing can change the functions of the stomatognathic system (breathing, sucking, chewing, swallowing, and speech), functions that affect vital and social aspects. ${ }^{(4)}$

The literature has demonstrated that oral breathing in children and adults with severe asthma can cause changes in the structures and functions of the stomatognathic system, which are represented, for example, by maxillary atresia and a high-arched palate; protrusion of the tongue between or against the dental arches; open bite and crossbite; hypotonic lips and lip occlusion with muscle tension; and inappropriate patterns of breathing, chewing, and swallowing. ${ }^{(5-8)}$
The static and mobile structures of the stomatognathic system act jointly and synchronously to perform the functions of breathing, sucking, chewing, swallowing, and speech. One can hypothesize that a change in an upper airway structure may change its corresponding function, such an example being that missing dental units will affect chewing. When a structure or function is changed, the other structures and functions may play their roles in a way befitting that new condition, one such example being that of hypotonia of the tongue leading to changes in executing swallowing movements.

Severe asthma can be identified by difficulty in controlling the disease or achieving treatment response, as well as by the presence of at least one of the following indicators: poor symptom control, as indicated by an Asthma Control Questionnaire (ACQ) score > 1.5 or an Asthma Control Test score $<20$; frequent exacerbations requiring two or more doses of systemic corticosteroids ( $>3$ times a day) in the previous year; severe exacerbations in the previous year, with at least one requiring hospitalization or mechanical ventilation; airflow limitation after bronchodilator use, with an $\mathrm{FEV}_{1}<80 \%$ of predicted; and frequent symptoms of nocturnal asthma and limitation 
in physical activities. ${ }^{(9-11)}$ Patients with severe asthma tend to show a high rate of allergic rhinitis, one of the clinical symptoms of which is nasal obstruction, and consequently have predominantly oral breathing. In such cases, the phonoarticulatory organs are positioned improperly and can lead to impairment of the functions of sucking, chewing, swallowing, and speech. Therefore, the objective of the present study was to describe orofacial muscle function in patients with severe asthma.

\section{METHODS}

This was a cross-sectional study of a consecutive sample selected in an asthma referral center-Programa de Controle da Asma e da Rinite Alérgica da Bahia (ProAR, Bahia State Program for the Control of Asthma and Allergic Rhinitis)-in the city of Salvador, Brazil. The inclusion criteria were as follows: having been diagnosed with severe asthma in accordance with the Global Initiative for Asthma criteria(12); and being 18 to 85 years of age. The exclusion criteria were as follows: having a neurological disorder, a genetic syndrome, a heart disease, a debilitating disease, facial trauma, cognitive deficit, or difficulty in understanding and performing the requested movements; having a history of head and neck surgery; and being pregnant.

Of the 160 subjects invited to participate in the study, all completed a sociodemographic questionnaire and the 6-item ACQ (ACQ-6), with the cut-off point for control being 1.5. ${ }^{(13)}$ The evaluation of muscle function consisted of observation of the face and oral function, following a validated protocol.(8) The data for FEV were obtained from medical records, which had to have been completed within twelve months previously.

To calculate the sample size required to estimate the frequency of myofunctional dysfunction in patients with severe asthma, we used the PEPI-Sample software (Sagebush Press, Salt Lake City, UT, USA) and the following parameters: a confidence level of $95 \%$; an estimated prevalence of myofunctional changes in the general population of $30-40 \%$; population from which the sample was drawn: approximately 2,000 severe asthma patients enrolled in the ProAR; and a difference in prevalence of $10 \%$ as being acceptable. To achieve the study objective, the required sample size was estimated at 145 patients. Allowing for a loss to follow-up rate of $10 \%$, a sample of 160 patients was determined.

Data were tabulated and analyzed with the IBM SPSS Statistics software package, version 20.0 (IBM Corporation, Armonk, NY, USA). Quantitative variables were expressed as mean \pm standard deviation or as median (interquartile range). Qualitative variables were expressed as absolute and relative frequencies. Proportions were compared with the chi-square test. Two means were compared with the Student's t-test for independent samples. Values of $p<0.05$ were considered statistically significant.
The present study was approved by the Research Ethics Committee of the Federal University of Bahia (Protocol No. 088/2010; Additional Resolution No. 41/2013). Written informed consent was given by the patients at the time they agreed to participate in the study.

\section{RESULTS}

A total of 160 adult patients (age $\geq 18$ years) were invited to participate in the evaluation of orofacial muscle function in patients with severe asthma. On the basis of the GINA criteria for classification of asthma, ${ }^{(12)} 126$ patients (79\%) had controlled asthma and $34(21 \%)$ had uncontrolled asthma. Table 1 shows the sociodemographic aspects of the severe asthma patients enrolled in the ProAR, providing data on gender, skin color, level of education, family income, age, BMI, spirometry, and ACQ-6 scores.

At the time of the evaluation of muscle function, 4 of the 160 invited patients ( 3 with severe controlled asthma and 1 with severe uncontrolled asthma) were excluded because they were unable to perform the requested movements. Figure 1 shows, by level of asthma control, the results for dental arch condition and presence/absence of fixed or removable dental prostheses in the severe asthma patients enrolled in the ProAR.

Figure 2 shows, by level of asthma control, the results of the evaluation of masticatory function (solid food: milk bread) in the severe asthma patients enrolled in the ProAR.

Figure 3 shows, by level of asthma control, the results for swallowing function (solid food and liquids) in the severe asthma patients enrolled in the ProAR.

The evaluation of orofacial muscle function, the responses on the ACQ- 6 , and the spirometric data revealed changes in breathing, voice, tongue mobility,

Table 1. Sociodemographic aspects, as well as clinical and spirometric characteristics, of the patients with severe asthma included in the study $(\mathrm{N}=160){ }^{\text {a }}$

\begin{tabular}{lc}
\multicolumn{1}{c}{ Variable } & Patients \\
Gender (female) & $123(76.9)$ \\
Skin color (brown) & $100(62.7)$ \\
Level of education & $80(50.0)$ \\
(<9 years of schooling) & \\
$\begin{array}{l}\text { Family income } \\
\text { (one time the national minimum }\end{array}$ & $80(50.0)$ \\
wage) & \\
Age, years & $51.5 \pm 12.6$ \\
BMI, kg/m ${ }^{2}$ & $29.0 \pm 5.2$ \\
$\begin{array}{l}\text { Pre-bronchodilator FEV } \\
\text { \% of predicted }\end{array}$ & $63.7(49.6-76.0)$ \\
Post-bronchodilator FEV & \\
$\%$ of predicted & $69.5(57.5-82.0)$ \\
ACQ-6 score & $0.66(0.50-1.33)$ \\
\hline
\end{tabular}

ACQ-6: 6-item Asthma Control Questionnaire. ${ }^{a}$ Values expressed as mean \pm SD or as median (interquartile range). 


\section{A}

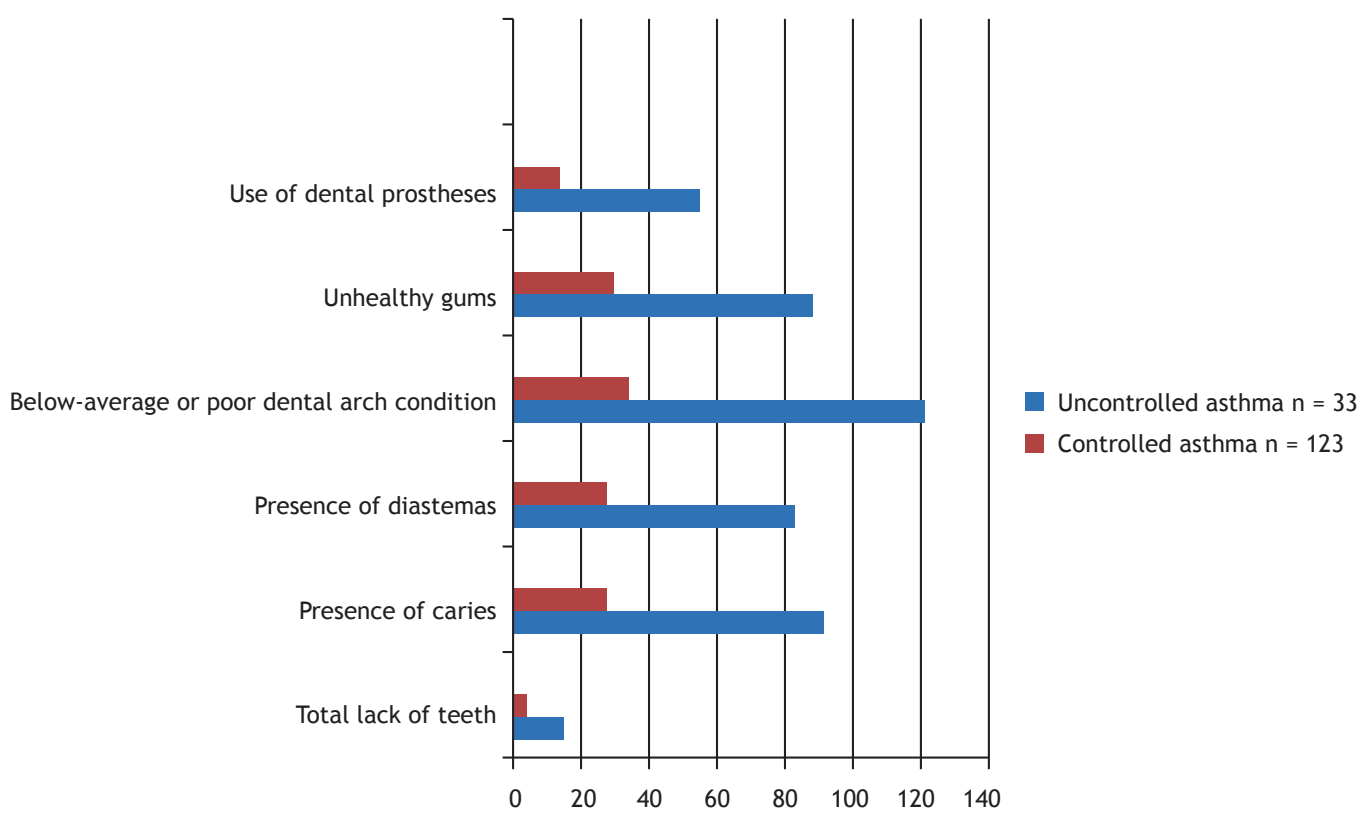

Figure 1. Comparison of dental arch characteristics in patients with severe asthma, by level of asthma control. Chisquare test; $\mathrm{p}<0.05$.

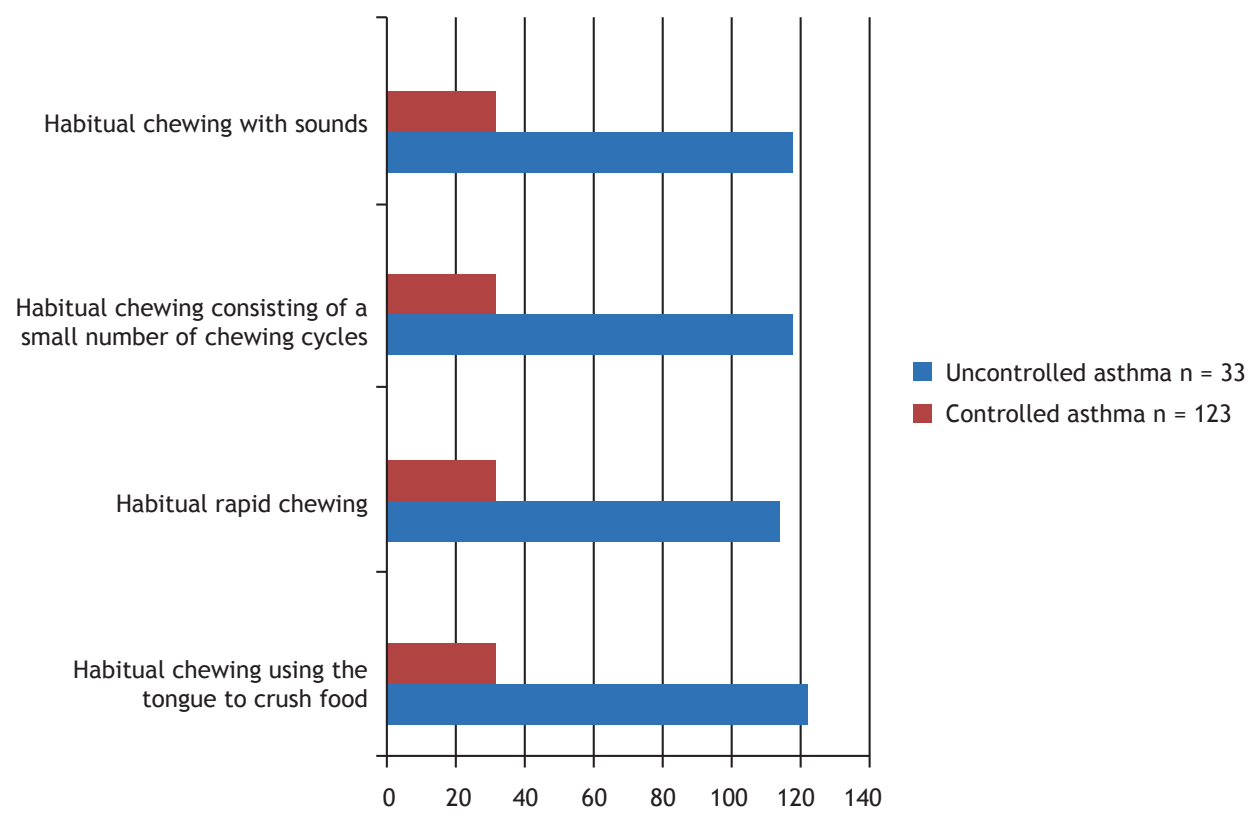

Figure 2. Comparison of masticatory function (solid food) in patients with severe asthma, by level of asthma control. Chi-square test; $p<0.05$.

masticatory function, and swallowing function. To gain a better understanding of these changes in asthma patients, the variables were analyzed by comparing these results on the basis of the two asthma control measures used. Table 2 shows, by $\mathrm{FEV}_{1}$ in $\%$ of predicted after bronchodilator use, the results of the statistical analysis (chi-square test) for tongue mobility, masticatory function, swallowing function, and voice complaints.

Table 3 shows, by level of asthma control as determined by the ACQ-6, the results of the statistical analysis (chi-square test) for tongue mobility, masticatory function, swallowing function, and voice complaints.

\section{DISCUSSION}

Our study results revealed that the frequency of changes in the stomatognathic system was high in patients with severe controlled asthma as well as in those with severe uncontrolled asthma. Two references were used as parameters for assessing asthma control: an objective one and a subjective one. Spirometry is an 


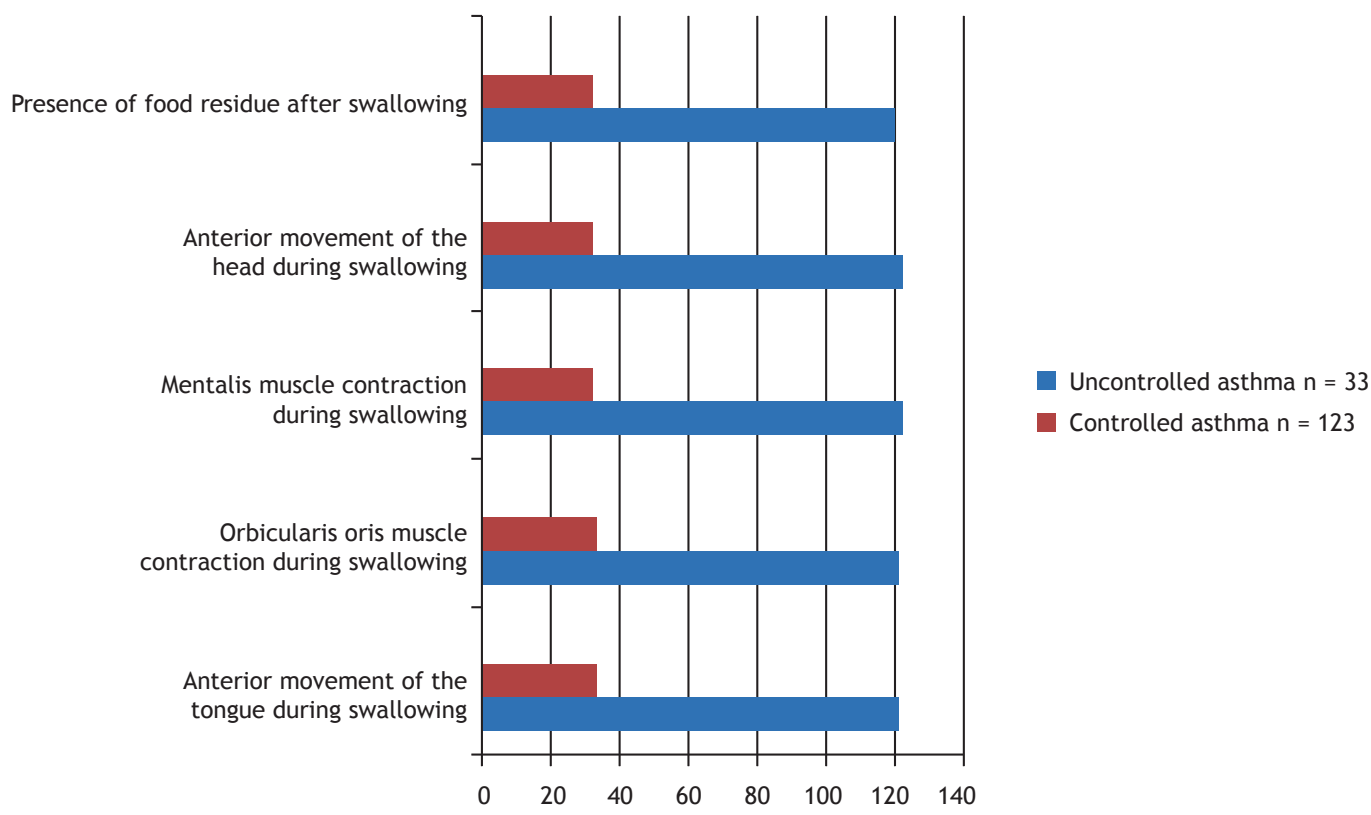

Figure 3. Comparison of swallowing function in patients with severe asthma, by level of asthma control. Chi-square test; $\mathrm{p}<0.05$.

objective test and provides pre- and post-bronchodilator $\mathrm{FEV}_{1}$ values. The ACQ is a subjective questionnaire for assessing asthma control that uses patients' memories and perceptions of their health status in the last seven days. The two parameters were associated with the variables studied.

In the present study, the results for the muscles and functions of the stomatognathic system were associated with asthma severity both with the use of FEV $_{1}$ and ACQ-6 score. Campanha et al. also observed associations between changes in the stomatognathic system and $\mathrm{FEV}_{1}$ in patients with uncontrolled asthma. ${ }^{(14)}$ In contrast, when asthma patients undergo speech therapy to restore a nasal breathing pattern, it can be seen that the clinical and functional improvement relative to an oronasal breathing pattern is evidenced

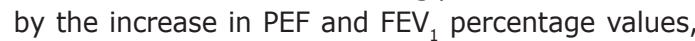
indicating the superiority of nasal breathing. ${ }^{(15)}$

In the present study, voice changes (Tables 2 and 3 ) were common in the asthma patients and can be described as hoarseness, throat clearing, scratchy voice, dry throat, burning sensation when talking, and faulty or difficult voice. The literature shows that asthma treatment can affect patients' voices. The findings of the present study corroborate those of Stanton et al., who concluded that impaired voice quality is common in patients with asthma and that the Grade-Roughness-Breathiness-Asthenicity-Strain system (GRBAS), which is a voice assessment scale, should be included in ear, nose, and throat assessment and in speech pathology assessment in asthma patients. ${ }^{(11)}$

Regarding the posture of the articulators, the findings of the present study were as follows: a habitual anterior tongue posture; a low tongue tip posture (on the floor of the mouth); a lowered posture of the tongue dorsum; a broad and tall maxilla; use of dental prostheses; and an elongated, edematous uvula. Corroborating these results, Berlese et al. found several orofacial changes in oral breathers, such as dry, open lips; a short, hypofunctioning upper lip; a full, everted lower lip; a lowered, hypotonic tongue; maxillary atresia and a high-arched palate; open bite and crossbite; hypotonic orofacial muscles; a flat nose with small nostrils; and protruding upper teeth. ${ }^{(7)}$

We found that $18.3 \%$ of our study participants were totally edentulous. As for dental arch condition, it was possible to observe caries and diastemas in the teeth, regardless of their position; poor overall condition; unhealthy gums; and use of fixed or removable dental prostheses. In a study of children with asthma conducted in 2007, Shashikiran et al. found an association between bronchodilator use, causing local effects such as a decrease in salivary $\mathrm{pH}$, and changes in salivary secretion levels and composition, which explains the increased incidence of caries and periodontal disease and draws attention to need for more effective hygiene as a means of preventing caries. ${ }^{(16)}$ Another study, which found asthma to be associated with orthodontic changes, facial symmetry, and Angle's classification of dental occlusion, observed the presence of crossbite, overbite, and diastemas, ${ }^{(17)}$ corroborating the findings of the present study.

Changes in masticatory function include crushing food with the tongue and chewing rapidly and insufficiently. Da Cunha et al. suggested that chewing duration tends to be decreased in asthma patients. Breathing difficulties and incoordination of breathing may be associated with decreased chewing duration, since asthma patients have difficulty in maintaining the balance required for breathing during feeding. ${ }^{(18)}$ 
Table 2. Data from the evaluation of orofacial muscle function in adults with asthma, by $\mathrm{FEV}_{1}$ in $\%$ of predicted after bronchodilator use. ${ }^{\mathrm{a}}$

\begin{tabular}{|c|c|c|c|}
\hline Variable & $\begin{array}{c}\mathrm{FEV}_{1} \geq 80 \% \\
(\mathrm{n}=52)\end{array}$ & $\begin{array}{c}\mathrm{FEV}_{1}<80 \% \\
(\mathrm{n}=101)\end{array}$ & p* \\
\hline Tongue, flaccid tone & $19(35.8)$ & $54(51.9)$ & 0.06 \\
\hline Tongue, asymmetric sucking & $14(26.4)$ & $34(32.7)$ & 0.47 \\
\hline Tongue, changes in the 4 cardinal points & $3(5.8)$ & $14(13.9)$ & 0.18 \\
\hline Habitual open-mouth chewing & $4(7.7)$ & $25(24.8)$ & 0.02 \\
\hline Habitual chewing more on one side & $46(88.5)$ & $92(91.1)$ & 0.58 \\
\hline Difficulty in swallowing bread & $15(28.8)$ & $38(37.6)$ & 0.37 \\
\hline Mentalis muscle contraction during water swallowing & $51(98.1)$ & $100(99.0)$ & 1.00 \\
\hline Difficulty in swallowing water & $9(17.3)$ & $34(33.7)$ & 0.04 \\
\hline Chocking during water swallowing & $13(25.0)$ & $37(36.6)$ & 0.20 \\
\hline Voice problems & 27 (51.9) & $82(81.2)$ & 0.01 \\
\hline
\end{tabular}

aValues expressed as n (\%). *Chi-square test or Fisher's exact test.

Table 3. Data from the evaluation of orofacial muscle function in adults with severe controlled asthma or severe uncontrolled asthma, as determined by the 6-item Asthma Control Questionnaire (ACQ-6). ${ }^{\text {a }}$

\begin{tabular}{lccc}
\multicolumn{1}{c}{ Variable } & \multicolumn{2}{c}{ Patients $^{\text {b }}$} & p $^{*}$ \\
& $\begin{array}{c}\text { Controlled asthma } \\
\text { (n = 123) }\end{array}$ & $\begin{array}{c}\text { Uncontrolled asthma } \\
\text { (n = 33) }\end{array}$ & 0.25 \\
Tongue, flaccid tone & $55(43.7)$ & $19(56.0)$ & 0.30 \\
Tongue, asymmetric sucking & $36(28.6)$ & $13(38.2)$ & 0.12 \\
Tongue, changes in the 4 cardinal points & $11(9.0)$ & $6(18.1)$ & 0.14 \\
Habitual open-mouth chewing & $21(17.0)$ & $9(27.3)$ & 0.65 \\
Habitual chewing more on one side & $111(90.2)$ & $30(91.0)$ & 0.01 \\
Difficulty in swallowing bread & $32(26.0)$ & $22(66.6)$ & 0.62 \\
Mentalis muscle contraction during water swallowing & $121(98.4)$ & $33(100.0)$ & 0.05 \\
Difficulty in swallowing water & $31(25.2)$ & $14(42.4)$ & 0.26 \\
Chocking during water swallowing & $39(31.7)$ & $25(76.0)$ & 0.66 \\
Voice problems & $87(71.0)$ & $13.2)$ & \\
\hline
\end{tabular}

avalues expressed as $\mathrm{n}(\%)$. ${ }^{\mathrm{C} C o n t r o l l e d}$ asthma: ACQ-6 scores $\geq 1.5$; and uncontrolled asthma: ACQ-6 scores < 1.5.

${ }^{*}$ Chi-square test or Fisher's exact test.

Using the tongue to help chewing, promoting food crushing, is consistent with the result of Lemos et al., who show that chewing is a learned function and may undergo changes. ${ }^{(6)}$ The patients in the present study made a lot of random chewing sounds. This result may be associated with the high frequency of oral breathers in the study population. Oliveira et al. define masticatory performance as a measure of the ability to grind food.(19) They believe that nasal obstruction produces sounds and changes in the posture of the tongue, lips, and jaw. Therefore, oral breathers, as well as asthma patients, do not eat well, undermining their craniomaxillary and orofacial development.

Studies of the functions of the stomatognathic system draw attention to the fact that the age at which an individual develops a mature swallowing pattern is controversial, ranging from 18 months to 6 years of age. Lemos et al., in 2009, pointed out that there is a relationship between oral breathing and the presence of changes in the swallowing pattern. ${ }^{(6)}$ Drozdz et al. reported that the act of swallowing depends on a complex and dynamic process using structures in common with the act of breathing, and, therefore, respiratory problems can cause swallowing difficulties. ${ }^{(20)}$ Berlese et al. agreed on the fact that oral breathing causes functional changes, such as adaptive swallowing, which can be characterized by the association of lip action, mentalis muscle action, and tongue protrusion, which occurs because of decreased tongue tone and a lowered tongue posture. ${ }^{(7)}$ In an attempt to correct these changes, the perioral muscles, including the orbicularis oris and the mentalis muscle, act more actively to reestablish the lip seal required for proper breathing. ${ }^{(7)}$

We emphasize the importance of the originality of the present study, which involved adults with severe asthma. The limitations of the present study are considered to be the lack of a control group, the fact that the study's convenience sample was drawn consecutively, the probability that the subjective responses on the ACQ- 6 negatively affected the correct perception of asthma control, and the lack of an otolaryngologist to diagnose and quantify the presence of allergic rhinitis. However, this loss of information is in line with the literature.

Our study results revealed that the frequency of changes in the stomatognathic system affecting muscles and structures was higher in patients with severe uncontrolled asthma than in those with severe controlled asthma; that the frequency of oronasal 
breathing, dental arch changes, and voice changes was high in patients with severe asthma, regardless of the level of asthma control; and that the frequency of changes in the stomatognathic system affecting the functions of breathing, chewing, and swallowing was higher in patients with severe uncontrolled asthma than in those with severe controlled asthma.

\section{ACKNOWLEDGMENTS}

We would like to thank the ProAR team for their genuine willingness and cooperation at the times of data collection. We would also like to thank the severe asthma patients enrolled in the ProAR for being so available, cheerful, interested, and cooperative at all times in the present study.

\section{REFERENCES}

1. Global Initiative for Asthma - GINA. [homepage on the Internet] Bethesda: Global Initiative for Asthma. [cited 2015 Apr 1]. Pocket Guide for Health Professionals Updated 2015. [Adobe Acrobat document, 28p.]. Available from: http://ginasthma.org/wp-content/ uploads/2016/01/GINA_Pocket_2015.pdf

2. Salles $C$, Cruz AA. Vias Aéreas Unidas. Rinite Alérgica: Conhecendo Melhor. 1st ed. São Paulo: Conexão Editorial; 2010, vol 1, p. 177-91.

3. Kairaitis K, Garlick SR, Wheatley JR, Amis TC. Route of breathing in patients with asthma. Chest. 1999;116(6):1646-52. http://dx.doi. org/10.1378/chest.116.6.1646

4. de Felicio CM, de Oliveira MM, da Silva MA. Effects of orofacial myofunctional therapy on temporomandibular disorders. Cranio. 2010;28(4):249-59. http://dx.doi.org/10.1179/crn.2010.033

5. Abreu RR, Rocha RL, Lamounier JA, Guerra AF. Prevalence of mouth breathing among children. J Pediatr (Rio J). 2008;84(5):467-70. http:// dx.doi.org/10.1590/S0021-75572008000600015

6. Lemos CM, Wilhelmsen NS, Mion Ode G, Mello Júnior JF. Functional alterations of the stomatognathic system in patients with allergic rhinitis: case-control study. Braz J Otorhinolaryngol. 2009;75(2):268 74. http://dx.doi.org/10.1016/S1808-8694(15)30789-8

7. Berlese DB, Fontana PF, Botton L, Weimnann AR, Haeffner LS. Myofunctional characteristics of obese mouth and nose breathers. Rev Soc Bras Fonoaudiol. 2012;17(2):171-6. http://dx.doi. org/10.1590/S1516-80342012000200012

8. Castro MS, Toro AA, Sakano E, Ribeiro JD. Evaluation of ora functions of the stomatognathic system according to the levels of asthma severity. J Soc Bras Fonoaudiol. 2012;24(2):119-24. http:// dx.doi.org/10.1590/S2179-64912012000200005

9. Fonseca JA, Botelho C. Severe asthma: definition [Article in Portuguese]. Rev Bras Alerg Imunopatol. 2006;29(2):70-6.

10. Chung KF, Wenzel SE, Brozek JL, Bush A, Castro M, Sterk PJ, et al. International ERS/ATS guidelines on definition, evaluation and treatment of severe asthma. Eur Respir J. 2014;43(2):343 73. Erratum in: Eur Respir J. 2014;43(4):1216. http://dx.doi org/10.1183/09031936.00202013

11. Stanton AE, Sellars C, Mackenzie K, McConnachie A, Bucknall CE. Perceived vocal morbidity in a problem asthma clinic. J Laryngol Otol. 2009;123(1):96-102. http://dx.doi.org/10.1017/S002221510800323X

12. Global Initiative for Asthma. Global strategy for asthma management and prevention. Bethesda: National Institutes of Health; 2011.

13. Leite M, Ponte EV, Petroni J, D’Oliveira Júnior A, Pizzichini E, Cruz AA. Evaluation of the asthma control questionnaire validated for use in Brazil. J Bras Pneumol. 2008;34(10):756-63. http://dx.doi. org/10.1590/S1806-37132008001000002

14. Campanha SM, Freire LM, Fontes MJ. Impact of asthma, allergic rhinitis and mouth breathing in life quality of children and adolescents. Rev CEFAC. 2008;10(4):513-9. http://dx.doi.org/10.1590/S1516 1846200800040001

15. Campanha SM, Fontes MJ, Santos JL. Dyspnea in patients with asthma, allergic rhinitis and mouth breathing. Rev CEFAC 2012;14(2):268-73

16. Shashikiran ND, Reddy W, Raju PK. Effect of antiasthmatic medication on dental disease: dental caries and periodontal disease. J Indian Soc Pedod Prev Dent. 2007;25(2):65-8. http://dx.doi. org/10.4103/0970-4388.33450

17. Faria VC, de Oliveira MA, Santos LA, Santoro IL, Fernandes AL. The effects of asthma on dental and facial deformities. J Asthma. 2006;43(4):307-9. http://dx.doi.org/10.1080/02770900600623305

18. da Cunha DA, da Silva HJ, Nascimento GK, da Silva EG, da Cunha RA, Régis RM, et al, Analysis of the masticatory process of asthmatic children: Clinical and electromyographic research. Int Arch Otorhinolaryngol. 2012;16(3):358-64

19. Oliveira RL, Noronha WP, Bonjardim LR. Masticatory performance evaluation in patients with nasal and mouth breathing [Article in Portuguese]. Rev CEFAC. 2012;14(1):114-21. http://dx.doi. org/10.1590/S1516-18462011005000112

20. Drozdz DR, Costa CC, Jesus PR, Trindade MS, Weiss G, Neto AB et al. Pharyngeal swallowing phase and chronic cough. Int Arch Otorhinolaryngol. 2012;16(4):502-8. 